\title{
Corporate Sustainability: Study of Factors that Affect Corporate Towards Organizational Sustainability in Today Fast-Changing World
}

\author{
Sumas Wongsnuopparat ${ }^{1} \&$ Wei Chunyang ${ }^{2}$ \\ ${ }^{1}$ Ph.D., Johnson Graduate School of Management, Cornell University, United States of America MBA, Tepper \\ School of Business, Carnegie Mellon University, United States of America \\ ${ }^{2}$ Master of Business Administration, Bangkok University, Bangkok, Thailand \\ Correspondence: Wei Chunyang, Master of Business Administration, Bangkok University, Bangkok, Thailand. \\ E-mail: wei.chun@bumail.net
}

Received: April 30, 2021

Accepted: June 2, $2021 \quad$ Online Published: June 7, 2021

doi:10.5539/jms.v11n2p56

URL: https://doi.org/10.5539/jms.v11n2p56

\begin{abstract}
Sustainability has always run through social and economic activities. As significant economies have competed for their interests in the past few years, this situation has caused a global economic depression. Additionally, this situation worsened due to the spread of the COVID-19 pandemic around the world. The international politics, economy, and Culture are undergoing unprecedented destruction and challenges from the COVID-19 pandemic that has caused businesses in many countries and regions to close or are about to face bankruptcy. More and more employees are getting laid off every day since the COVID-19 began. Even employees who are employed are feeling unsecured. So, in the face of uncertainties and difficulties facing corporations worldwide, we need to find a better way to extend the company's life cycle in a more structured and sustainable manner.

The main research question for this study is "What are the factors that have significant effects on organizational sustainability?" In this study, twelve independent variables including Leadership (L.S.), Management (M.N.), Culture (C.T.), Structure (S.T.), Workforce diversity (W.D.), Organizational age (O.A.), Staff age (S.A.), Mindset (M.S.), Technology (T.N.), Organizational dimension (O.D.), Group structure (G.S.), Business locations (B.L.) and one dependent variable called Sustainability (SUS) is the studied. This study aims to understand the structural relationships among these potential variables that could influence corporate sustainability. The dataset utilized to test the hypothesis postulated in this study using Structural Equation Models (SEM). This study suggested that the Leadership, Management, and Staffing Age significantly affects organizations towards organizational sustainability. Considering the different politics, economy, and cultural backgrounds in countries and industries, the study also found that some irreconcilable factors affect the performance of leadership, management, and staff ages. Thus, this study identified effective leadership, management, and staff age as strategies to lead organizations further towards organizational sustainability. The results of this study provide some valuable suggestions for all companies facing the COVID-19 threats right now to bring back to life and become more sustainable in the years to come and provide some evidence for future researchers to explore this field further.
\end{abstract}

Keywords: corporate sustainability, leadership, management, staff age, SEM

\section{Introduction}

Sustainability has run through our society, economy, and throughout our lifetimes. But the COVID-19 pandemic has impacted the economy, society, geopolitical, environment, technology, industry, human behavior, human mentality, all significant suffering destruction, and reset. Economic depression has become the most concerned topic for most people in the next few years. As we can see from the information provided by "Global Economic Prospects" (Bafees, 2021), the consensus forecast of global GDP (percent), started to decrease from 1.97\% from March 2020 to April 2020, the consensus forecast of global GPD (Percent) is $-2.68 \%$. By May 2020, the percentage had down to $-4.36 \%$. The economic depression has caused a series of social problems. Therefore, we had summarized information from $(\mathrm{al}, 2020)$ the number of people in the poverty range had increased from 643.3 million in 2019 to 729.3 million in 2020. The number will achieve 735.7 million in 2021. In this article, they mentioned that "the COVID-19 has pushed an additional 88 million people into extreme poverty in this year" and "In a worst-case scenario, the figure could be as high as 115 million" and "Many of the newly poor are likely 
to be engaged in informal services, construction, and manufacturing - the sectors in which economic activity is most affected by lockdowns and other mobility restrictions." As they mentioned that "the COVID-19 has triggered a global crisis like no other - a global health crisis that, in addition to an enormous human toll, is leading to the deepest global recession since the Second World War." "A crisis is an event that can destroy an organization and its employees' products, services, and the financial condition of a business enterprise like a corona outbreak. An economic crisis, if left unchecked, can cause concern. This crisis is an event with a broad scope of society" (Hertati, The effects of economic crisis on business finance, 2020).

The COVID-19 had significant impacts on the company life cycle. From the information mentioned in (Marinelli, 2015) we can see that the average life span of a company listed in the S\&P 500 index has decreased by more than 50 years in the last 100 years, from 67 years 1920 s to just 15 years today. More than three-quarters of the S\&P 500 will be companies not known to us today. Only 10\% of the listed companies on the FTSE100 30 years ago exist today in the U.K. But the COVID-19 has made this situation worse than before and make the company life cycle shorter and shorter, as we can see from the information provided by "Impact of the COVID-19 Pandemic on Trade and Development; TRANSITIONING TO A NEW NORMAL" (Antunes, 2020), The three major economies with significant export declines during the COVID-19. Significantly, the significant declines in automotive and chemicals industries, although China has some growth in textiles and office machinery, communication equipment, whatever this global economic depression, is stronger affects the company life cycle and makes its situation further worse than before. The COVID-19 also affects the global foreign direct investment market. From the article (Antunes, Impact of the COVID-19 Pandemic on Trade and Development: Transitioning to a New, 2020), we can see that Foreign direct investment flows decreased by up to 40 percent in 2020 from their 2019 values close to $\$ 1.6$ trillion.

Summarizing the information and data from the above articles, we know the company life cycle is getting shorter and shorter has been affected by the economic depression and the COVID-19 pandemic worldwide. But what are the reasons to make the company lifecycle getting shorter and shorter? The first reason is that more and more organizations are attempting to moving hard towards organizational sustainability. What is corporate sustainability? According to the definition of sustainability, "Three conceptions of triple bottom line business sustainability and the role for HRM" (Colbert, 2007), organizational sustainability is "Keep the business going." As we know, many companies have closed down and experienced bankruptcy during the COVID-19 pandemic, and they cannot keep running their business. The second reason is that the lifestyle and business models have changed, the traditional company life cycles have been old-fashioned, and technology companies and technology-driven industry speed up for communication and delivery, to make the changes in competitive edge smaller and smaller "The Company Life Cycle" (Marinelli, The Company Life Cycle, 2015) as we see that some of the companies and industries still can stand firm in this fast-changing world. The third reason is that there is a mismatch in the interpretation of the environment and strategies' conduct, which impacted the industry's overall performance (Maylin-Aguilar, 2020). The fourth reason is that the most successful organization will have a firm grasp of shortening product life cycles within their industry and put strategies in place to allow them to adapt quickly to changing markets, enabling new sources of revenue to be generated (Pierce, 2020). The answer from the above articles helps make readers further understand why some of the companies hard to towards organization sustainability and why organizations must realize organizational sustainability. Every company must work hard towards corporate sustainability. "The most powerful business case for adopting a responsible and sustainable approach to business would appear to be the emergence of globalization, which has considerably changed the role and relationships of business, governments, and other key stakeholders" (Jamali, 2019).

This research aims to investigate what corporate sustainability is and what factors affect corporate towards organizational sustainability in today's fast-changing world, and how these factors affect corporate towards organizational sustainability. Meanwhile, we will also investigate the barriers that affect organizations' realized organizational sustainability is. Because after we summarized the finding from previous theories, articles, and papers, we see many factors they did not include, mentioned, and translated. They may be some articles and authors they had said. This research will analyze and summarize the relationship of these factors (Leadership, Management, Culture, Structure, Workforce Diversity, Organization Age, Staff Age, Mindset, Technology, Group Structure, and Business Location). This research will benefit from providing guidelines and suggestions for industrial, business, and future research.

\section{Objectives of Study}

The objective of this study was to investigate all the factors that affect corporate towards organizational sustainability possibly. The factors identified were Leadership, Management, Culture, Structure, Workforce diversity, Organization age, Staff age, Mindset, Technology, Organization dimension, Group structure, and 
Business locations.

\section{Scope of Research}

Scope of variables: 12 significant independent variables; leadership, Management, Culture, structure, workforce diversity, organization age, staff age, mindset, technology, organization dimension, group structure, business locations, and one dependent variable; Sustainability.

Scope of population/sample: This research focused on the responses from a target group of 400 individuals interested in studying factors influencing organizations towards organizational Sustainability in Bangkok, Thailand, and China.

Scope of applied research methodology: This research primarily focused on Quantitative research methodology using Structural Equation Modeling (SEM) to analyze the structural relationship of all the proposed influential variables on corporate sustainability.

Scope of data analysis and interpretation for hypothesis testing. The final data was collected, analyzed, and tested for the hypothesis over one month, spanning between the end of March 2021 to end of April 2021.

\section{Literature Review}

\subsection{Organizational Sustainability}

The popularity of sustainability continues to increase, and more and more organizations, people, communities, would like to accept and understand the concept of sustainability. According to the information from "The evolution of sustainable development theory: types, goals, and research prospects" (Shi, 2019), we can see that the theory of Sustainable has gone through three periods: the embryonic period (before 1972), the molding period (1972-1987), and the developing period (1987-present). In the meantime, the concept of sustainability is continuously evolving from pursuing the single goal of natural resource sustainability to Millennium Development Goals and Sustainable Development Goals. But there have some challenges that affect the trend of popularity of sustainability spread in the organizations. We got the information from (Duarte 2017). They said that "sustainability learning only took place informally in the organizational studies. The organization did not have a formal system connect to sustainability learning in its rules, process, and practices." Like "The driving forces of sustainability" (Stoughton, 2012) had mentioned that" different perspectives towards sustainability exist.

We are incredibly grateful to the previous articles for giving us great help and guidance to understand the meaning and significance of sustainability better. In this research, we will focus more on the importance of organizational sustainability in business. As (Spiliakos 2018) mentioned in "the effect business has on environment" and "the effect business has on society," the goal of a sustainable business strategy is to make a positive impact on at least one of those areas. When companies fail to assume responsibility, the opposite can happen, leading to issues like environmental degradation, inequality, and social injustice".

We know that corporate sustainability is not an easy goal for any corporation from the above articles and information. But if we can further eliminate or reduce the pressures and barriers that affect organizational sustainability, we may have more possibilities to realize sustainable corporate development. The article "Strategies responses to institutional pressures for sustainability: The role of management control systems" (Wijethilake, Strategic responses to institutional pressures for sustainability: The role of management control systems, 2017) had told readers that there some of the pressure came from institutional to affects corporate towards organizational, in this article make readers understand that management control system interaction with the institutional force for sustainability, we may create the potential long-term value for the organization if we can go through strategies response and operations. But the practice and learning process are also the pressures and barriers that affect corporate toward organizational sustainability. From the article "Sustainable organizational learning and corporate entrepreneurship: a conceptual model of sustainable practices in organizations" (Brandi, 2020), we can see that the barriers and pressures are about continuous feedback from individual, group, organizational and social levels. Meanwhile, organizations have to filter this feedback further and apply it in all phases of the change process.

\subsection{Leadership}

In the business world, people engaging in why an organization's leadership is essential? As "5 Reasons Why Leadership Is Essential in A Health Work Culture" (Sengupta, 2020) mentioned in his article, "Great leaders bring change," "Great leaders learn continuously," "Great leaders are always thinking for the good of their clients and employees," "Great leaders communication well with their customers," and "Great leaders refine their 
employees' skills."

The abilities of leaders and leadership are some of the factors that affect corporate towards organizational sustainability. As we mentioned above, sustainability is related to complex concepts, so leaders can have comprehensive abilities to manage the corporation. They have possessed the skills as following "Predict through complexity, think through complex problems, engage groups in dynamic adaptive organizational change and have the emotional intelligence to adaptive engage with their own emotions associated with complex problem-solving" (Metcalf, 2013). Thus, as this author said, "Leaders and leadership is a key interpreter of how sustainability of the organization "links" to the wider systems in which the organization sits, and executing that link well requires unusual leaders and leadership system."

\section{H10: Leadership has no impact on organizations towards corporate sustainability in this fast-changing world.}

H11: Leadership significantly impacts organizations towards corporate sustainability in this fast-changing world.

\subsection{Management}

Management is the keyword in many industrial fields, business fields, and research fields, etc. To further explore the relationship between management and organizational sustainability, we had summarized the information provided "management and organizational sustainability tool (Most)" (Management and organizational sustainability tool; a guide for users and facilitators, 2004). This article had to make readers understand that make a map about the development of crucial management components and through these results to planning improvements. Monitoring progress is a company's management advantage, a high-quality management map help organization clear identification of critical management components that require further development can facilitate organizational diagnosis and identification of management improvement priorities, to make the level of organization management further improve, but it also requires skillful facilitation with group participants. Generally, the change has always gone with challenges, and each time of transition will affects the interest of the group of stakeholders. As the article "Applying stakeholder theory in sustainability management: Links, similarities, Dissimilarities, and a conceptual framework" (Horisch, 2014), there three challenges of managing stakeholder relationships for sustainability: strengthening the particular interest and empowering stakeholders to act as intermediaries for nature and sustainable development, but in this article, they had to make readers understand that through education, regulation, and sustainability-based value creation for stakeholders to address these three challenges.

To further understand how corporate can realize organizational sustainability, we had read and summarized the critical information mentioned in several articles. The first article is "Sustainable development of organizations through total quality management" (Todorut, 2012). They think that every organization must implement total quality management and strategies management principles to help achieve sustained success, satisfy all the interested parties' requirements and expectations, and sustainable development. The second article, "Continuing the evolution: Towards sustainable HRM and sustainable organizations" (Freitas, 2011), has given reads about HRM towards sustainability as a new step in HRM evolution. This article thinks sustainable HRM is essential for helping corporate and society towards organizational sustainability.

H20: Management has no impact on organizations towards corporate sustainability in this fast-changing world.

H21: Management significantly impacts organizations towards corporate sustainability in this fast-changing world.

\subsection{Culture}

The relationship between Culture and corporate is getting closer and steady. From the information provided in the article "Corporate Culture: The Theory and the Practice," we can see that the corporate Culture developed since around the 1960s and then going steadily until current, but the situation in organizational Culture is different, the organizational Culture has grown faster than corporate Culture, although the trend of organizational sustainability had decreased, it still higher than corporate. Because "A possible solution is for organizations to develop a sustainability-oriented organizational culture that engages employees with the sustainability change and that develops a leadership supportive of the engagement of their employee," and from the finding of this article, we know that "organization's culture is being changed at the artifact levels and, partially, at the values and beliefs level of their cultures" (Negro, 2019). Culture needs to continue developing and accepting new concepts and thinking to make the Culture an advantage to organizational sustainability. Despite some of the challenges on the way, but for corporate better towards organizational sustainability, we must bravely face the challenges 
and take each challenge as an opportunity. As the article "Applying cultural evolution to sustainability challenges: an introduction to the special issue" (Brooks, 2018) mentioned that "an important challenge for applications of cultural evolution and CMSLs is that these are "date hungry" frameworks, as outlined in Klink at et al. That said, these papers presented important initial steps in refining the application of these cultural evolutionary models for understanding whether and in which context sustainable social-ecological system can emerge and persist."

H30: Culture has no impact on corporate towards organizational sustainability in this fast-changing world.

H31: Culture significantly impacts corporate towards organizational sustainability in this fast-changing world.

\subsection{Structure}

Organizational structure may offer its advantages for corporate better development. Still, there is not only one structure. A different organizational structure has other effects on corporate operations and Management, As article "Business model for sustainability: A co-evolutionary analysis of sustainable entrepreneurship, innovation, and transformation" (Schaltegger, 2016) the authors had told readers that "Particularities of the business models of sustainable nice market pioneers have identified in earlier research, but little known about the dynamic role of business models for sustainable entrepreneurship processes aiming at upscaling ecological and socially beneficial niche models or sustainability upgrading of conventional mass-market players." Meanwhile, depending on different countries and industries filed, choose a suitable organizational structure for corporate getting better development and generate more profits, as the article from "The evolution of sustainable business model innovation: evidence from a sharing economy platform in China" (Hu, 2019), from the finding of this article, they had told about that the sustainable business model has had a significant impact on the development of a sharing economy platform.

Due to the world getting closer than before, it creates challenges and opportunities for each corporation, and this is time to exam for each organizational structure. The article "New trend of Economic Globalization" (Gurgu, 2016) that globalization has continuously brought challenges to organizational structure. Exceptionally, these challenges more knotty than regular times. The article of "The relationship between globalization and e-commerce: Turkish Case" (Aydin, 2014) had provided some ideas about what is the situation about globalization and organizational structure and how organizational structure to face the challenges from globalization, from this article we understand that there are mutual relation rather than one-way relation in the international business, although the level of technology and telecommunication could affect to this relation. Although innovation and difficulty in adopting strategies and framework to support organizational structure face challenges from globalization, Abouzeedan (2013) states in "organizational structure theories and open innovation paradigm" that not all organizational structures and organizing-mechanism theories are responsive to the needs of the open paradigm set (Abouzeedan, 2013).

\section{H40: Structure has no impact on corporate towards organizational sustainability in this fast-changing world.}

H41: Structure significantly impacts corporate towards organizational sustainability in this fast-changing world.

\subsection{Workforce Diversity}

Workforce diversity may have affected company performance, employee retention, and engagement. As we see in "Does workplace diversity impact a business?" (Global, 2020), companies with more diverse leadership teams report higher innovation revenue - $45 \%$ of total revenue versus just $26 \%$, according to a 2018 BCG report". "A 2017 report from The Kapor Center and Harris Poll found that workplace culture drives turnover, significantly affecting the retention of underrepresented groups, and costing the tech industry more than $\$ 16$ million each year. Workplace diversity extends across the employee's work career and personal life, as mentioned in the article "Impact of Workplace Diversity" (Foma, 2014).

"Diversity is an important part that all employees have to deal with at one point during their careers." Workforce diversity may create opportunities for corporate better development. In the article, "six opportunities that companies may receive when pursuing a strategy that values diversity include cost advantages, improved resource acquisition, greater marketing ability, system flexibility, and enhanced creativity and better problem solving managing cultural diversity." Workforce diversity may have affected an employee's life and employee's work performance. The article "Impact of workforce diversity management on employees' outcomes: testing the mediating role of a person's job match" $(\mathrm{Li}, 2020)$ gives examples of the relationship between workforce diversity and employee outcomes. This article shows that workforce diversity management positively impacts a person's job match, job satisfaction, and job performance. 
Workforce diversity will be bringing meaningful change for the organization towards organizational sustainability. As the article "Three reasons diversity is important in driving sustainability" (Tellz, 2017) mentioned, diversity is embedded in the definition of sustainability, variety adds value across multiple perspectives, and diversity enriches collaboration. This article makes readers understand that good organizational sustainability has to support by an excellent corporate performance. Good workforce diversity can create a perfect administrative account. From the information mentioned in the article "The effect of workforce diversity on organizational performance of Selected firms in Nigeria" (Ogbo, 2014), we had further understood that workforce diversity has a positive relationship with customer-related issues in an organization. Education could be one of the tools to help manage workforce diversity to help the company enhance high profitability.

\section{H50: Workforce diversity has no impact on corporate towards organizational sustainability in this fast-changing world.}

\section{H51: Workforce diversity significantly impacts corporate towards organizational sustainability in this} fast-changing world.

\subsection{Organizational Age}

To further explore the relationship between age, Organization, Management, organizational behaviors, and how it affects corporate towards organizational sustainability, we found several articles about organizational age that affect organizational development and affect organizational sustainability. The first article is "An organizational theory of age effects" (Lawrence, 1987). In this article, the researcher had told readers that "the central thesis of the theory is that age distributions drive the development of age norms that produce age effects." We know that age can contribute to employee turnover, promotion probabilities, performance, and work involvement from this article. The second article is "organizational age \& size impact on brand management" (VanAuken, 2007). They had explained the difference between smaller | younger Organizations and larger | older Organizations to found the brand problems of small and large organizations. Younger organizations have to develop a strong brand identification through less expensive means and find a highly effective way to building brand awareness. Finally, summarize the data and information from comprehensive research and study to further confirm their consumers. For larger and older organizations, they have to cooperate with the senior leadership team to building a distinctive brand image and adjust the marketplace positioning by business strategies and organizational design. The third article, "organizational age; the fall 2017 state of grant seeking report" (Adams, 2017), says that the corporate age is the critical factor influencing the grant-seeking experience. We can see that "most young organizations $(81 \%)$ reported annual budgets under $\$ 1,000,000$. Only $11 \%$ of very mature organizations reported annual budgets under $\$ 1,000,000$, so we can see that the organizational age has a positive relationship with organizational annual budget size and organizational sustainability. The last article is organization's age and organizational citizenship behavior (OCB), performance criteria at SMEs. Case study - Bucharest - I1 fov development regio" (Popescu, 2015). This article had told readers about the relationship between an organization's age and organizational citizenship behavior in small and medium enterprises.

Organizational age may affect the administrative operation and customer services, even corporate towards organizational sustainability. The article "Organizational age, structure, and orientations towards client" (Rosengren, 1968) mentioned that" young hospitals expressed a broad but short-term (plus-lateral-minus-longitudinal) orientation towards their clients. At the same time, old hospitals manifested a specifically focused but long-term (minus-lateral-plus-longitudinal) orientation towards the client biography.

H60: Organizational age has no impact on corporate towards organizational sustainability in this fast-changing world.

H61: Organizational age significantly impacts corporate towards organizational sustainability in this fast-changing world.

\subsection{Staff Age}

The article "Who is the older worker" told readers that older employees value and the risks and challenges from the more senior employee. The employer would like to hire an employee who possesses good experience, knowledge, work ethic. Thus, they can reduce the lost work time and create more profit for the company compare with the young employee, but in the meantime, the older workers may bring more management challenges for employers and managers. For example, more senior employees may suffer more health and physical problem, like acute injuries, eye or hand burns, etc., and these risks will affect the organizational performance. How is the young employee? Although the young employee may have many advantages over the old employee, they have a better potential for team building, productivity, and workplace morale. They can also 
bring a more creative perspective and a different way of thinking to corporate and business. Still, they also exist several management challenges for corporate. To further explore the effects of young employees and old employees incorporate, we refer to "Hiring young employees advantages and disadvantage" (Reddy). The young employee may have more passion, energy, and more to accept new work than the old employee. Still, they also exist one of the potential risks: lack of stability and lack of skills. The young employee may more easily manage and have higher productivity than the old young employee, but they also hard to follow the discipline and accessible to failure of handling pressure. However, the company may spend the lower cost for young hire employee. Still, no matter hiring a young employee or an old employee, the hiring decision-making has to depend on how it can match this corporate's goals. The article" Youth adapt faster than senior to unexpected events, study find" and" Why is organizational change so har" (Madsen, Why is organizational change so hard? 2018)" had further make readers understand the characteristics of young employee and old employee, and why organizational so hard to adjust the proportion between young employee and senior employee, as this article mentioned that "Older adults were less able to overcome their habitual responses when unexpected sequences arose" and "When they really need to perform well at a given task, older adults should probably seek out an environment where they can focus on the task at hand without distraction", although a lot of managers and leaders they had seem this problems, but this is hard to motivate and engage their employees in the organization changing process, and fears is one of the critical factors affects people adopt organizational changing, because employee they fear that they will lose something of value and there exists many uncertain factors on the way of administrative changing process.

A strategic and reasonable mix of the corporate staff's age may bring positive impacts on corporate development. The article "Eight reasons for employing a mixed-age workforce" (Features, 2003) had mentioned that a mixed-age workforce would "reduce turnover and increased retention, improved morale, and motivation. The ability to tap new markets, becoming an employer of choice, makes the organization more attractive to investors, greater customer satisfaction, enable change management, and cost savings and more flexible budgets". The strategic and reasonable mix of the staff age in the corporate can also positively impact internal corporate management. Thus, we had summarized important information mentioned in the article "Organizational age cultures: The interplay of chief executive officers age and attitudes towards younger and older employees (Zacher)" is the CEO age was positive young employee if the CEOs have a positive attitude towards the young employee, and CEOs was damaging to the young employee if CEOs have a less positive attitude towards the young employee, and CEO age was favorable to the old employee if CEOs have positive towards the old employee, but they don't have significant hostile towards the more senior employee. The "age and employee green behaviors: a meta-analysis" (Wiernik, 2016) had to make readers understand that the organizational behaviors may affect by staffage in the organization, as they mentioned that "Contrary to popular stereotypes, aged showed a small positive relationship with pro-environmental behaviors, suggesting that older adults engaged in these workplace behaviors slightly more frequently."

\section{H70: Staff age has no impact on corporate towards organizational sustainability in this fast-changing world.}

\section{H71: Staff age significantly impacts corporate towards organizational sustainability in this fast-changing} world.

\subsection{Mindset}

Different mindsets can lead people to go to different ways of thinking and affect personal life in the future. To further explore the meaning of mindset and how it affects people's lives and people's work, we summarized the related information about mindset from the book "Mindset; The New Psychology of Success Paperback-Illustrated, December 26, 2007". We can see that there two kinds of mindsets, which are a growth mindset and a fixed mindset. In a growth mindset culture, people believe their most basic abilities and qualities can be developed and cultivated through dedication and hard work. The growth mindset helps you try new things and help you have more passion and ambition to pursue your goals and improve your performance. But people of the people easy to give up on challenging tasks or even avoid those challenges, so we call that kind of the people who hold the fixed mindset.

Some people believe that if something they cannot control or cannot change, they will remain limited in their thinking and behaviors. Because as the article mentions, "most people believe their basic qualities, like their intelligence or talent, are simply fixed traits. They spend their time documenting their intelligence or talent instead of developing them. They also believe that talent alone creates success-without effort. They're wrong". So, as we can see, the people who hold fix mindset cannot change the complicated things by their abilities, to make them lose confidence and hard to face the challenges from life, work, family, and other stuff from social 
life. Finally, different people have different mindset settings, and different mindsets influence their ideas and behaviors. The information from this book makes use to know that mindset is a tool for people who want to improve themselves. Meanwhile, mindset is a barrier to stop people cannot change everything.

To better set a proper mindset for corporate employees, we must consider employees' emotions as the essential factors that affect the setting mindset. As the article (Dawson, 2019) mentioned that "mindset as a state of mind encounters between mental states and the environment often evoke emotions, and when the same emotions are repeatedly associated with a particular mental state, that state becomes cathected with those emotions."

The authors of the article "Emotional thresholds and change agent success in corporate sustainability" (Blomfield, 2016), they had further investigated this issue. They told readers that how employees respond to sustainability messages is influenced by how organizational support for sustainability. In the meantime, how employees perceive those individuals and their efforts' success is controlled by the intensity of emotions that change agents display. From this article, we understand that sustainability is an emotional issue. Change agents play an essential role in bringing positive emotional impacts that can motivate employees and organizations to create green outcomes.

H80: Mindset has no impact on corporate towards organizational sustainability in this fast-changing world.

H81: Mindset significantly impacts corporate towards organizational sustainability in this fast-changing world.

\subsection{Technology}

More and more corporations have applied advanced technologies to enlarge their corporations. As examples mentioned in the article "Exciting future technology concepts will transform enterprise process" (Nimbalkar, 2019), readers understand that technology has further changed corporate development. First is the Intelligent Enterprise System". According to the renowned Evans Data Corporation, today's ERP software industry is the main target of artificial intelligence and machine learning developers. $40 \%$ of all industry leaders are attempting to use these technologies in ERP systems. Machine learning is the major attraction in many of them". The second is Connected Environment for Enterprises, "The next and outstanding advance in this regard is the "Enterprise Internet of Things" that enables the realistic "thing" with embedded devices of computing to contribute to the business process. In this dynamic environment, devices are interconnected and share real-time data. This help reduces traditional working methodology for enterprise executives and increases work efficiency with ease". The third is Could-based ERP, "Since early 2019, there has been a spectacular jump in traction of could-based ERP system. Demand for could-connected ERP systems has increased primarily due to operational capacity that could provide to businesses. According to more than a dozen research articles, the cloud-based ERP market will reach $\$ 29$ billion by the end of this year, increasing by almost $\$ 11$ billion from 2016.

Technology is not all good for corporate and organizational development because the technology also disrupts many corporate management systems and negatively impacts administrative operations. As the article "Understanding the impact of technology on business" (Wilson, 2018), "one of the biggest complaints about technology's impact on businesses is the lack of human interaction," "it's easier for something to go wrong, information to be stolen, and your business to be compromised through technology."

H90: Technology has no impact on corporate towards organizational sustainability in this fast-changing world.

H91: The technology dimension significantly impacts corporate towards organizational sustainability in this fast-changing world.

\subsection{Organizational Dimension}

The article "The dimension of organizational character and Its Impacts on Organizational Performance in Chinese Context" (Yu, 2018) provided suggestions about the formation and cultivation of organizational character would directly improve an organization's business performance as well as its growth potential. So, we can see that the difference in organizational dimensions has a strong influence on managing their employees, and then, it further impacts the organization's performance.

"Centralization" (M, 2018), the centralization organization dimension can make the management team hold a better command to subordinates in business. Hence, it makes the management team don't need to spend much time in their office and reduce the expenses from company administrative. A mature centralization organization dimension will have clear ideas about organizational vision and set up the appropriate policy for different levels of subordinates to improve the organization's work quality and organization profit. From the article "Principles 
of accounting, Volume 2: Managerial accounting" (Franklin, 2019), we had found an example about the organization with a centralization organization dimension, as they said that Apple is an example of a business with a centralized management structure. Within Apple, much of the decision-making responsibility lies with the Chief Executive Officer (CEO), Tim Cook, who assumed the leadership role within Apple following the death of Steve Jobs.

About the disadvantages of centralization, in "the disadvantage of centralized control in a business." (Bianca, 2019) argues that centralization has "stifled creativity, limited communication, inflexible decision-making, and danger of losing a key decision-maker."

Formalization. The advantages and disadvantages of the formalization organization dimension. We had summarized the relevant answer mentioned in the article "Advantages and disadvantages of formalization essay" (Agarwal, 1983). The formalization organization dimension is an excellent tool to set rules and regulations to control the organization. Meanwhile, a suitable formalization organization dimension can improve the rationality of organizations, for example, through rationality rules and regulation to complete a smooth transition of authority. One of the disadvantages of formalization it has taken a long time and across many rules and regulations to complete one decision making.

Hierarchy. The hierarchy system had widespread use in many corporations globally and continuously affected corporate management and operations. To further explore the effect of the hierarchy system, we had summarized the information provided by the (Team I. E., Hierarchical structure: definition and examples, 2021). The hierarchy structure can make employee easier and faster to understand their company structure and career path. Through the hierarchy system, employees further understand the various levels of leadership and help the employee build a sense of team spirit and loyalty. Then, the authority of hierarchy gets more improving. Order also prevalent using in other filed, so we had summarized the information provided by the paper "Hierarchical organization: Definition, Types of structure, advantages \& disadvantages" (Bhasin, Hierarchical Organization: Definition, Types of Structure, Advantages \& Disadvantages, 2020), the hierarchy had widespread use in the political system, as we can see that in some countries have president, the prime minister, and speaker, etc., and Hierarchy also extensive use in the military with arm chief stands on the top position and next to him are general, and the religious group also use hierarchy system manage the people in their organization. The hierarchy is a management tool that leads different organizations to run their own business. Meanwhile, its nature affects organizational behaviors. Finally, the article "Hierarchy and organization: Toward a general theory of hierarchical social systems" (Diefenbacha, 2013), they had further investigated that why hierarchy structure can live in society for a long time and why it can accept by almost all of the populations, the reason is that the hierarchy as one of the essential elements to direct affects best ideas humanity and affects our produced such as democracy, equality, fairness, sociology, psychology, management, and economics.

Hierarchy stricture also has several disadvantages, which are limited by their nature. For example, one decision-making has to wait and get confirmation from several departments. It will increase the cost of administration and decrease the action. In a hierarchy structure, all the orders and information almost come from top to down. It is easy to cause poor communication in the organization.

To further explore how corporate can reduce the negative impacts from the hierarchy system and better adjust their hierarchy system to pursue organizational sustainability goals better, we summarized the information from several articles. From the article "The Hierarchy of Authority in Organizations" (Blau, 1968), many supervisors and managers have less communication with employees and subordinates, thereby caused the adverse effects from the top-down centralization management. Still, from the findings of this article, we know that many large organizations had developed multilevel hierarchies and reduced the direct intervention by management. Then, employees can have more automation and personnel standards to transform from a squat structure with centralized control to a high-level format with decentralization.

Routinization. There are several articles had further explored the effect of Routinization on organization operation and management. In the article "Routinization, Work Characteristics and Their Relationships with Creative and Proactive Behaviors" (Ohly, 2006), Routinization may positively affect creativity and related behavior. The result of this article had told readers that "Routinization is generally positively related to creative and proactive behaviors. But Routinization has its limitation, and its benefits may affect by technology development. The article "The routinization of work" (Kipnis, 1990) suggests ideas about modern production technology that have further reduced the ability of people to compete with each other. To further reduce people's confidence, personal worth, and people's lives, even affect organization operations. In the article "Routinization of work and the quality of working life: A study among Canadian Nurses" (Baba, 1989), they had further 
investigated issues of the relationship between Routinization, work, people life, and organization. Thus, readers can understand that Routinization of work and the quality of working life will affect job satisfaction, job involvement, role ambiguity, role conflict, role overload, job stress, job scope, organizational commitment, and turnover intention".

Specialization. From the example provided by the article (mamunjum, 2018). We further understand that work specialization may influence employee work and affects company performance, so we had summarized the examples mentioned in this article. KFC uses a hierarchical structure to manage their employees, and at the operation level, they divide employees by Customer Service Team and Food Service Teams. The cashier takes the order, the chef prepares the food, and the brand manager supervises the whole process to ensure the work runs smoothly and effectively. In Google, to complete work faster and obtain more efficiency, their employees are divided into three groups: Function-based, Product-based, and Flatness. The function-based group set up sales operation teams, an Engineering \& Design Team, a Product Management Team, etc. Work specialization also has several disadvantages and may bring negative impacts on corporate management. As (zahra_malik_00 04-01-16) mentioned, quality may suffer if workers become bored by the lack of variety in their work. If they do the same job every day, workers' skills may suffer and eventually replace machinery.

Training. To further explore the effects of training, we had found several articles which had mentioned the impact of exercise on or corporate management and corporate operations. The article "Building a learning organization" (Garvin, 1993) told readers that because most companies failed to grasp an essential truth and cause failed program and cannot achieve, so continuous improvement is help organization to better building their advantages. The article "How does organization training influence employee performance" (Lorette) makes readers understand the relationship between training and organization dimension and how good training can positively impact corporate sustainability. We had summarized the information had mentioned in this article. The training organization dimension can make the employee feel more loyal to your business, work hard, and study more to increase organizational Culture and organization profit. But once we decided to start training our employee, we must consider the following issues as the disadvantages of training in corporate management. First, as we know that training employees will cause high costs, the costs may include travel, training facilities, in-house training development, and equipment. Second, time may become the second important factor because corporate employees spend time away from their job and life, even if they have to spend more time completing the training in other cities and countries. However, online learning can help them save some of the time. Training with unbalance proportion ratio will be caused a situation of less communication because after the employee completes their training, they may not need to ask others to forget the suggestion and help.

H100: Organization dimension has no impact on corporate towards organizational sustainability in this fast-changing world.

H101: Organization dimension significantly impacts corporate towards organizational sustainability in this fast-changing world.

\subsection{Group Structure}

In the article "Group and their effects in organizations" (Asu, 2015), we understand that the groups' system has positive and negative influences on its structure and function. There are several advantages from group structure which is "normative effect of group on the individual," "impact of the group on the change of individual attitude," "impact of the group on the individual's productivity," "impact of the group on the decision-making process," "impact of the group on the performance (social acceleration). Although a group's structure provides several positive impacts on corporate management and the members in the corporate, group structure may also be restrictive and have negative impacts on corporate development. As this article mentions, the groups, which the employees form between themselves in the organization, and informal organization, formed by these groups, may significantly affect the operation of formal organization." People cannot work alone without an organization or a group in the corporation. Every employee has to adopt the feature of each group structure. Still, these features of group structure sometimes bring adverse effects on group and personal health, as in the article, they mentioned that "the individual, conflicting with the group, is sick. As this sickness may be a mental disorder, it may also be a behavioral, emotional, and thought disorder. It is not sufficient that the individual becomes a specific group to be healthy. In other words, unless the worker becomes the full member of any group in the organization, they will not reach psycho-social peace (Homans, 1971).

Finally, there may be adverse effects between group structure and personal characteristics, and personal behavior. If individuals establish relationships with other persons and groups in the organization, they have the opportunity to control the political, economic, and social power threatening them (Fujishin, 2013). 
H110: Group structure has no impact on corporate towards organizational sustainability in this fast-changing world.

H111: Group structure significantly impacts corporate towards organizational sustainability in this fast-changing world.

\subsection{Business Locations}

Geography factors have further become essential for business development. Some of the research had further investigated the relationship between geographical factors and business failure, as the article "Geographical factors and business failure: an empirical study from the Madrid metropolitan area" (Mate-Sanchez-Val, 2017), in this article, they had provided some evidence about the role of geography on business failure in urban environments, they through based on 3125 industrial small and medium firms confirms, they think geographical location between firms, external, economics agents and transport facilities has a determinant impact on business success or failure.

For a macro scales, the relationship between the business location and business failure and success, as the article "Effect of Economic Globalization" (Effect of economic globalization, 2019) mentioned that "Globalization providers businesses with a competitive advantage by allowing them to source raw materials where they are inexpensive. Globalization also allows organizations to take advantage of lower labor costs in developing countries while leveraging the technical expertise and experience and more developed economies". But globalization also brings some adverse effects on corporate and social-economic development. Meanwhile, globalization also disrupts some of the traditional business systems and affects the interest of some stakeholders. As the article mentioned that "any change has winners and losers, and the people living in communities that had been dependent on jobs outsourced elsewhere often suffer."

H120 Business locations have no impact on corporate towards organizational sustainability in this fast-changing world.

H121: Business locations significantly impact corporate towards organizational sustainability in this fast-changing world.

Based on related literature and previous studies discussed above, the researcher developed a conceptual framework to study the factors that could impact organizational sustainability 


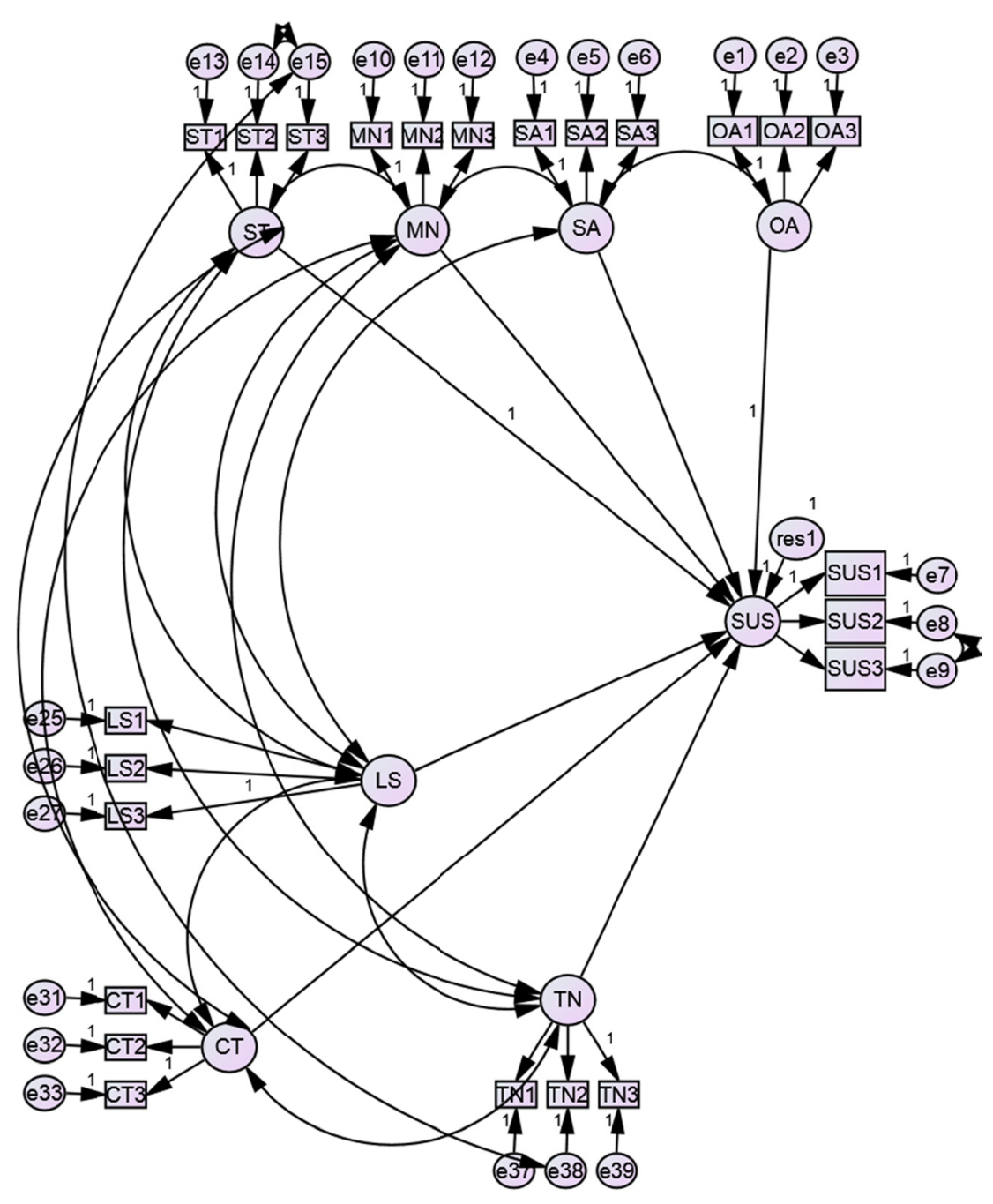

Figure 1. Conceptual model

\section{Research Finding and Data analysis}

This research aimed to study the factors that affect corporate towards organizational sustainability. In this chapter, the researcher presents the study's findings along with the analysis of the results. Research data was collected from 400 respondents through survey questionnaires and measured and validated through the Statistical Package for the Social Sciences (SPPS) data analysis program.

We used SPPS to explore further and analyze the data about RMR, GFI, RMSEA, and p-value to get the findings of this study. The result is present below.

Table 1. RMR, GFI

\begin{tabular}{lllll}
\hline Model & RMR & GFI & AGFI & PGFI \\
\hline Default model & .079 & .905 & .877 & .700 \\
Saturated model & .000 & 1.000 & & \\
Independence model & .165 & .528 & .487 & .486 \\
\hline
\end{tabular}


Table 2. RMSEA

\begin{tabular}{llccc}
\hline Model & RMSEA & LO 90 & HI 90 & PCLOSE \\
\hline Default model & .055 & .049 & .062 & .089 \\
Independence model & .131 & .126 & .137 & .000 \\
\hline
\end{tabular}

Since the RMSEA for this model is $.055(<.06)$, and the Goodness of Fit Index (GFI) value is .905 , the model seems to fit well according to the descriptive measures of fit.

More importantly, leadership (L.S.), Management (M.N.), and Staffing Age (S.A.) seem to have significant effects on corporate sustainability due to their p-values are all less than .05.

Table 3. P-value

\begin{tabular}{|c|c|c|c|c|c|c|c|}
\hline & & & Estimate & S.E. & C.R. & $\mathrm{P}$ & Label \\
\hline SUS & $<---$ & LS & .582 & .289 & 2.016 & .044 & \\
\hline SUS & $<---$ & $\mathrm{TN}$ & .136 & .162 & .840 & .401 & \\
\hline SUS & $<---$ & $\mathrm{MN}$ & -1.168 & .351 & -3.328 & $* * *$ & \\
\hline SUS & $<---$ & $\mathrm{ST}$ & 1.000 & & & & \\
\hline SUS & $<---$ & $\mathrm{OA}$ & 1.000 & & & & \\
\hline SUS & $<---$ & SA & -1.843 & .330 & -5.593 & $* * *$ & \\
\hline SUS & $<---$ & $\mathrm{CT}$ & .049 & .207 & .237 & .813 & \\
\hline OA1 & $<---$ & $\mathrm{OA}$ & 1.000 & & & & \\
\hline $\mathrm{OA} 2$ & $<---$ & $\mathrm{OA}$ & 1.105 & .125 & 8.841 & $* * *$ & \\
\hline OA3 & $<---$ & $\mathrm{OA}$ & 1.016 & .116 & 8.779 & $* * *$ & \\
\hline SA1 & $<---$ & SA & 1.000 & & & & \\
\hline SA2 & $<---$ & SA & 1.327 & .231 & 5.745 & $* * *$ & \\
\hline SA3 & $<---$ & SA & 1.474 & .263 & 5.609 & $* * *$ & \\
\hline SUS1 & $<---$ & SUS & 1.000 & & & & \\
\hline SUS2 & $<---$ & SUS & .233 & .037 & 6.239 & $* * *$ & \\
\hline SUS3 & $<---$ & SUS & .188 & .039 & 4.863 & $* * *$ & \\
\hline MN1 & $<---$ & $\mathrm{MN}$ & 1.000 & & & & \\
\hline MN2 & $<---$ & $\mathrm{MN}$ & .965 & .087 & 11.102 & $* * *$ & \\
\hline MN3 & $<---$ & $\mathrm{MN}$ & .770 & .086 & 8.940 & $* * *$ & \\
\hline ST1 & $<--$ & $\mathrm{ST}$ & 1.000 & & & & \\
\hline ST2 & $<---$ & $\mathrm{ST}$ & .945 & .108 & 8.778 & $* * *$ & \\
\hline ST3 & $<---$ & ST & .622 & .099 & 6.309 & $* * *$ & \\
\hline LS3 & $<---$ & LS & 1.000 & & & & \\
\hline LS2 & $<---$ & LS & 1.002 & .120 & 8.331 & $* * *$ & \\
\hline LS1 & $<---$ & LS & .664 & .098 & 6.786 & $* * *$ & \\
\hline СT3 & $<---$ & $\mathrm{CT}$ & 1.000 & & & & \\
\hline $\mathrm{CT} 2$ & $<---$ & $\mathrm{CT}$ & .920 & .125 & 7.334 & $* * *$ & \\
\hline $\mathrm{CT} 1$ & $<--$ & $\mathrm{CT}$ & .911 & .123 & 7.389 & $* * *$ & \\
\hline TN3 & $<---$ & $\mathrm{TN}$ & 1.000 & & & & \\
\hline TN2 & $<---$ & $\mathrm{TN}$ & .941 & .127 & 7.424 & $* * *$ & \\
\hline TN1 & $<---$ & $\mathrm{TN}$ & .789 & .110 & 7.203 & $* * *$ & \\
\hline
\end{tabular}

\section{Discussion}

Structural Equation modeling was used for this research, and all data from the sample size was calculated by SEM analogy resulting in 400 participants. We summarized the questionnaire results, the respondents with mixed male and female ratios, and other assorted items, such as age, status, level of education, monthly income, and professional quality. Still, most of them were married and over 50 years old. Most of them had bachelor's degrees or less than under bachelor's degrees. A small proportion of respondents had master's degree and doctor's degree, with the majority earning between 15,000 bath or less 15,000 baht and 15,001 baht to 30,000 baht, a small proportion of respondents earning between 100,000 baht to 150,000 baht, most of them working in state 
enterprise. The majority is of individuals engaging in the topic of corporate sustainability. We used a pilot sample and complete sample testing and exceeded the understanding level of reliability test through Cronbach's Alpha $(\alpha)$. Thus, we had further estimated and tested the theoretical relationship between each latent variable and observed variable based on reliability. The latent variable in this study was the independent, which include L.S. M.N., CT, S.T., W.D., OA, S.A., MS, TN, O.D., G.S., B.L., and dependent have B.L. factors, observed variables through survey testing were used 39 items in total, including e1 to e39 analyze the data.

In this research, there were a total of twelve hypotheses proposed. "A p-value higher than $0.05(>0.05)$ is not statistically significant and indicates strong evidence for the null hypothesis. It means we retain the null hypothesis and reject the alternative hypothesis. You should note that you cannot accept the null hypothesis. We can only reject the null or fail to reject" (McLeod, 2019). The hypotheses of leadership no impacts (or significant impacts) on corporate towards organizational sustainability, the hypotheses of management no results (or significant effects) on corporate toward organizational sustainability, the hypotheses of no impacts (or significant impacts) on corporate towards organizational sustainability their p-value are all less than .05 , which is mean we can accept these three hypotheses. Thus, leadership, management, staff age seems to have significant effects on corporate towards organizational sustainability.

\subsection{Why Have We Used SEM?}

SEM is a robust analytical framework encompassing an extensive array of statistical techniques (e.g., path analysis, confirmatory factor analysis). Path analysis models are highly flexible in terms of hypothesized relations among variables and concerning variable structure, thus enabling a broader range of research questions to be addressed. Path model provided a framework for moving away from overreliance on the somewhat simplified mindset associated with null-hypothesis significance testing (NHST), towards model-based reasoning (i.e., a mindset where the relationship between variables was viewed as part of a more extensive explanatory system, one which is evaluated as such) (Gruyter, 2020).

\subsection{Research Implications}

We had collected much information related to corporate sustainability and the background about the economy in this research and, based on this information, further explored factors that affect corporate towards organizational sustainability. After extensive research, read and noted related news, we had found some previous implications and limitations from previous research. We set twelve independent variables and one dependent variable to explore the factors most affect corporate towards organizational sustainability. The questionnaire results were contributed by 400 respondents from different countries, including China, Thai, Veneman, Singapore, Indian, Iran, with varying work statuses, for example, state enterprise, private enterprise, self-employed. Therefore, this research provided several implications to industries, other businesses, and researchers.

First, this research had further summarized the information relates to corporate sustainability development and further update the factors that may affect corporate towards organizational sustainability. This research created under this the COVID-19 pandemic time, global economic depression, high number unemployment, and most companies suffering closed and about to bankruptcy, and recovering plan, all of these has provided the examples for this research topic what is factors affects corporate towards organizational sustainability in this fast-changing world.

For industry, many factors bring adverse effects on corporates' organizational sustainability, especially under the current global COVID-19 epidemic, the sustainable development of enterprises is more threatened than before. It is mainly reflected in the company life cycle, and the company product life cycle is shorter and shorter. This research collected a lot of information about the development situations of various industries before the COVID-19 pandemic and the development situation under the COVID-19 pandemic. Some of the articles mentioned are about the future development of enterprises and how to recovery enterprises in the epidemic economy. This series of articles and real cases provides suggestions for the company's self-reflection, self-review, self-recovery, self-improvement, and some tips for the company's future development direction and corporate management direction.

Over the years, the world's business environments have changed rapidly, and world trade competition has become more and more fierce. The COVID-19 has calmed some of the competition, but the truth is that it has brought a significant blow to world business. Anyway, the COVID-19 will eventually pass, the world economy is constantly resetting, and sustainable business development may become a topic of our concern. In this research, we collected and analyzed the business development trends of the world's three major economies (China, the United States, European countries) before the COVID-19 pandemic and predicts the development trends after the COVID-19 pandemic. We hope that this related information can provide some suggestions for corporate business 
recovery and corporate economy recovery.

For future researchers, in this study, we had a thorough SEM model to analyze the results from the questionnaire with 400 respondents. The finding of this study indicated that leadership, management, and staff age had a significant impact on corporate towards organizational sustainability. Thus, this research present that each independent variable has a different effect on the dependent variable of this study. They also have an impact together with a significant relationship between each independent variable. This study further summarized and explored the relationship between each different variable that affects corporate towards organizational sustainability.

\subsection{Research Limitations and Recommendations for Future Research}

Although this research identified the factors that significantly affect corporate towards organizational sustainability, it is not without some limitations. Most of the respondents of this research belong to the people working in state enterprises; therefore, this research may have limited to the workplace. They're some of the limitations are that some respondents do not have the experience to live abroad. Some of the answers from them may be affected by the policies and development of the country in which they live. Therefore, future researchers are recommended to collect respondents from the people living in several countries (China, Thailand, India, Iran, Singapore) with different age groups, work status, gender, monthly income, and personal status. Finally, we hope this article that analyzes the factors that affect corporate sustainability can contribute to future researchers.

\section{References}

Abdulrahaman, S. (2013). Operational approach, functional approach, and development of management in the 21 st century. ResearchGate.

Abouzeedan, A. (2013). Organization structure theories and open innovation paradigm. ResearchGate.

Adams, C. M. (2017). Organizational age; the fall 2017 state of grant seeking report. Grant Station; your fast track to funding.

Agarwal. (1983). Advantages and Disadvantages of Formalization Essay. IvyPanda.

Ahmad, S. W. (n.d.). Theory of structures. Universiti Malaysia Pahang.

AIAqeel, A. A. (2012). Factors influencing the sustainable development of organizations. The University of Gloucestershire.

Aleksidze, N. (2020). Proper organizational Culture as a key Instrument for effective H.R. management. Saacademy.

Allen, L. (1958). Management and Organization. New York: McGraw-Hill Cambridge Dictionary.

Amoo, T. (2002). Workforce diversity: the key to survival and growth. ResearchGate.

Antunes, B. (2020). Impact of the COVID-19 Pandemic on Trade and Development: Transitioning to a New. United Nations.

Asu, M. S. (2015). Groups and their effects in organizations. European Scientific Journal.

Aydin, E. (2014). The relationship between globalization and e-commerce: Turkish Case. Procedia - Social and Behavioral Sciences, 150(15), 1267-1276. https://doi.org/10.1016/j.sbspro.2014.09.143

Baba, V. V. (1989). Routinization of work and the quality of working life: a study among Canadian Nurses. Operational Research and the Social Sciences, 679-684. https://doi.org/10.1007/978-1-4613-0789-1_103

Bafess, J. (2021). Global Economic Prospects. World bank group.

BeauteHealthy. (2020). What is Culture? types of Culture, elements of Culture, characteristics of Culture.

Bentler, P. M., \& Chou, C. P. (1987). Practical issues in structural modeling. Sociological Methods \& Research. https://doi.org/10.1177/0049124187016001004

Bernecker, K. (2019). Mind Theory. Social Psychology in Action, 179-191. https://doi.org/10.1007/978-3-030-13788-5_12

Bhasin, H. (2020a). Hierarchical Organization: Definition, Types of Structure, Advantages \& Disadvantages. Marketing91.

Bhasin, H. (2020b). Organizational hierarchy - definition, meaning, examples, advantages. Marketing91.

Bhattacharya, C. B. (2020). How workplace culture can support sustainable business. Brink The edge of risk. 
Bianca, A. (2019). The disadvantages to centralized control in a business. Chron.

Birk, M. (2020). Why leaders need meditation now more than ever. Harvard Business Review.

Blau, P. M. (1968). The hierarchy of authority in organizations. American Journal of Sociology, 73(4). https://doi.org/10.1086/224506

Blomfield, J. M. (2016). Emotional thresholds and change agent success in corporate sustainability. Emotions and Organizational Governance, 12. https://doi.org/10.1108/S1746-979120160000012007

Bovée, C. L. (1993). Management (1st ed.). New York: McGraw-Hill.

Brandi, U. (2020). Sustainable organizational learning and corporate entrepreneurship: A conceptual model of sustainability practices in organizations. Journal of Workplace Learning, 33(3), 212-228. https://doi.org/10.1108/JWL-05-2020-0084

Brooks, J. S. (2018). Applying cultural evolution to sustainability challenges: An introduction to the special issue. SpringerLink.

Chand, S. (2013). Training: Meaning, definition and types of training. Your article library Organizational Models in Training. Training Industry.

Chen, J. J. (2020). The Economic Impact of the COVID-19 in China: Evidence from City-to-City Truck Flows. School of Economics and Management, Tsinghuai University.

Chen, Y. S. (2011). Utilize structural equation modeling (SEM) to explore the influence of corporate environmental ethics: The mediation effect of green human capital. Quality \& Quantity, 47, 79-95. https://doi.org/10.1007/s11135-011-9504-3

CIPD. (2012). Responsible and sustainable business: H.R. leading the way. A collection of thought pieces February sustainable organization performance. Sustainable Organisation Performance.

Claas, L. (2015). Moral Impact of Design. Master thesis philosophy of science, technology and society university of Twente.

Clay, N. (2020). Why Mindset Matters as We Age. ILLUMINATION.

Cohen, J. (1988). Statistical Power Analysis for the behavioral sciences. Lawrence Erlbaum Associates, Publishers.

Colbert, B., \& Kurucz, E. (2007). Three conceptions of triple bottom line business sustainability and role of $H R M$. Human Resource Planning 30.

Colin, P., \& Julie, W. (2005). Exploring Rellability in Academic Assessment. Graduate Assistants, UNI Office of Academic Assessment.

Comrey, A. L., \& Lee, H. B. (1992). A first course in factor analysis (2nd ed.). Lawrence Erlbaum Associates, Inc.

Cortijo, V. (2019). The AGE model: Addressing ageism in the workplace through corporate social responsibility. Wiley Online Library. https://doi.org/10.1111/wusa.12387

Dawson, T. (2019). Mindset, emotion, \& learning. Theo Dawson.

Derler, A. (2019). Organizational Growth Mindset: The key to culture change? Ein Gastbeitrag. Leadership insiders.

Diefenbacha. (2013). Hierarchy and Organization: Toward a general theory of Hierarchical social systems. ResearchGate.

Duarte, F. de P. (2017). Sustainability learning challenges in a Brazilian government organization. Emerald Group Limited. https://doi.org/10.1108/IJOA-02-2015-0842

Duggan, T. (n.d.). How does organizational structure affect performance measurement? Chron.

Edwards, M. G. (2009). An integrative metatheory for organizational learning and sustainability in turbulent times. Emerald Group Publishing Limited. https://doi.org/10.1108/09696470910949926

E.G. Carmines, R. Z. (1979). Reliability and validity assessment. Reliability and Validity Assessment. https://doi.org/10.4135/9781412985642

Ekardt, F. (2009). Theory of Sustainability. Research Unit Sustainability and Climate Policy.

ERC. (2019). Workplace culture: what it is, why it matters, and how to define it. 
Escobar, M. R. (n.d.). Structural Equation Modeling: What is a latent variable? In The analysis factor.

Features, Employment Law. (2003). Eight reasons to employ a mixed-age workforce. Personnel today.

Foma, E. (2014). Impact of workforce diversity. Integrative Business \& Economics.

Franklin, M. (2019). Openstax.

Freitas, W. R. S. (2011). Continuing the evolution: towards sustainable HRM and sustainable organizations. ResearchGate.

Garvin, D. A. (1993). Building a learning organization. Harvard Business Review.

Giddens, A. (1986). The concept of structure. Social theory and modern sociology.

Global, Purdue University (2020). Does workplace diversity actually impact a business? Purdue University Global.

Griffin, D. (n.d.). The effect of business location to the business' success. Chron.

Grubler, A. (2015). Technology: Concepts and definitions. Cambridge University press.

Gruyter, D. (2020). On the benefits of structural equation modeling for corpus linguists. Corpus Linguistics and Linguistic Theory

Gurgu, E. (2016). New trends in Economic Globalization. The Journal of Economic Development, Environment and People, 5(1). https://doi.org/10.26458/jedep.v5i1.147

Haddad, R. E. (2019). The impact of 360 feedback appraisal system on organizational justice and sustainability: The mediating roles of gender and managerial levels. International Journal of Organizational Analysis.

Hanks, C. (2018). What is workforce diversity? Wonolo Emplify. 4 excellent examples of diverse and inclusive company cultures. Emplify What is workforce diversity? Human resources MBA.

Haque, A. (2020). The COVID-19 pandemic and the role of responsible leadership in health care: Thinking beyond employee well-being and organizational sustainability. Leadership in Health Services, 34(1), 52-68. https://doi.org/10.1108/LHS-09-2020-0071

Hayley, H, R. (1995). The structural equation modeling approach: Basic concepts and fundamental issues. APA PsyNet.

Hertati, L. (2020). The Effects of Economic Crisis on Business Finance. IDEAS. https://doi.org/10.32479/ijefi.9928

Horisch, J. (2014). Applying stakeholder theory in sustainability management: Links, similarities, dissimilarities, and a conceptual framework. Organization \& Environment, 27(4), 328-346 https://doi.org/10.1177/1086026614535786

$\mathrm{Hu}, \mathrm{H}$. B. (2019). The evolution of sustainable business model innovation: Evidence from a sharing economy platform in China. Sustainability. https://doi.org/10.3390/su11154207

ICS social requirement. (2017). Corporate staff definition (Chapter 1: Minimum age, Child labour, and young workers). Law insider.

Ifedi, C. (2020). Leadership style and organizational structure alignment: Impact on innovativeness and business performance. Georgia State University.

Indarti, N. (2004). Business location and success: The case of internet cafe business Indonesia. Gadjah Mada International Journal of Business. https://doi.org/10.22146/gamaijb.5543

Jamali, D. (2019). Adaptations of CSR in the context of globalization. ResearchGate. https://doi.org/10.5772/intechopen.79035

Janggu, T. (2014). Does good corporate governance lead to better sustainability reporting? An analyzing using structural equation modeling. Procedia - Social and Behavioral Sciences, 145(25), 138-145. https://doi.org/10.1016/j.sbspro.2014.06.020

Jenkins, W. (n.d.). Sustainability Theory. Berkshire encyclopedia of sustainability: The spirit of sustainability.

Jones, L. B. (2018). How your management style can affect business growth. Training zone.

Kaplan, D. (2001). Structural Equation Modeling. International Encyclopedia of the Social \& Behavioral Sciences, 15215-15222. https://doi.org/10.1016/B0-08-043076-7/00776-2 
Kipnis, D. (1990). The Routinization of work. Springer Link. https://doi.org/10.1007/978-1-4612-3294-0_6

Kline, R. B. (2015). Principle and practice of structural equation modeling. Guilford publications.

Kloefkorn, S. (2014). Why organizational structure is so important for small businesses. The Business Journals.

Koeber, A. L. (1952). Culture: A critical review of concepts and definitions. Harvard University Peabody Museum of American Archeology and Ethnology.

Kordestain, A. (2015). Emerging trends in sustainability research: A look back as we begin to look forward. ResearchGate. https://doi.org/10.1504/IJESD.2015.068602

Kruse, K. (2013). What is leadership? Forbes.

Kukreja, S. (2019). What is Management? Management study H.Q. The role of management. B.C. Campus OpenEd.

Lawrence, B. S. (1987). An organizational theory of age effects. ResearchGate.

Lazaric, N. (2012). Routinization of learning. Encyclopedia of the Sciences of Learning. https://doi.org/10.1007/978-1-4419-1428-6_246

Leonard, K. (2018). The definition of organizational management. Chron 5, Samiksha. Importance of Management to a modern business.

Levy, A. (2021). Investing in Growth Stocks. The Mottey Fool.

Li, W. J. (2020). Impact of workforce diversity management on employee's outcomes: Testing the mediating role of a person's job match. Journal Indexing and Metrics, 10(1). https://doi.org/10.1177/2158244020903402

Libraries. (2010). Principle of Management.

Linnenluecke, M. K. (2009). Corporate sustainability and organizational Culture. ScienceDirect.

Lorette, K. (n.d.). How does Organization training influence employee performance? Chron.

Lozano, R. (2021). Disrupting the brave new world: The COVID-19 effects on organization's sustainability efforts. Journal of Organizational Change Management, 34(3). https://doi.org/10.1108/JOCM-09-2020-0276

Madsen, S. (2018). Why is organizational change so hard? Liquid Planner.

Majaski, C. (2021). Working-age population. Investopedia Mindset on Wikipedia.

Major, D. A. (2016). The Importance of Organizational Leadership in Managing Work and Family. OXFORD HANDBOOKS ONLINE. https://doi.org/10.1093/oxfordhb/9780199337538.013.21

Mamunjum. (2018). What is work specialization? How it uses it Google and KFC. Steemit.

Mar, A. (2013). 21 types of management. Simplicable.

Mardani, A. (2017). Application of Structural Equation Modeling (SEM) to solve environmental sustainability problems: A comprehensive review and meta-analysis. Sustainability. https://doi.org/10.3390/su9101814

Marie, A. (1997). What are technology concepts? ITEEA.

Marinelli, D. (2015). The Company Life Cycle. DM EUROPE.

Martin, J. S. (2012). Global business etiquette: A guide to international communication and customs. Library of congress cataloging in publication data.

Mason, M. (n.d.). What is sustainable and why is it important. Environmental Science.

Mate-Sanchez-Val, M. (2017). Geographical factors and business failure: An empirical study from the Madrid metropolitan area. Economic Modelling, 74, 275-283. https://doi.org/10.1016/j.econmod.2018.05.022

McNamara, C. (2006). Field Guide to Consulting and Organizational Development: A Collaborative and Systems Approach to Performance, Change and Learning Paperback. Authenticity Consulting, LLC.

Merriman, K. K. (2016). Employees and sustainability: The role of incentives. Emerald Group Publishing Limited. https://doi.org/10.1108/JMP-09-2014-0285

Metcalf, L. (2013). Leadership for sustainability: An evolution of leadership abilities. ResearchGate.

Miller, A. (n.d.). Organizational structure \& management. Chron.

MSH. (2004). Management and organizational sustainability tool: A guide for users and facilitators. 
Management sciences for health.

Mumme, B. (2019). How to Build (At Any Age) a Growth Mindset. Benjamin Mumme.

Nasrin, R, K. (2011). Theory and Concept of Sustainable and Sustainable Development. Practical Sustainability, 1-22. https://doi.org/10.1057/9780230116368_1

National Geographic. (2019). Effect of economic globalization.

Negro, P. A. (2019). Driving organizational culture change for sustainability. MALMO UNIVERSITY Business culture; introduction to business culture. Passport to trade; a bridge to success.

Neubert, M. J. (2016). Developing sustainable management theory: Goal-setting theory based in virtue. Emerald insight. https://doi.org/10.1108/MD-05-2014-0312

Nielsen. (2015). The sustainability imperative: New insights on consumer expectations.

Nimbalkar, N. (2019). Exciting future tech concepts that will transform enterprise processes. Customer Think.

Northouse, P. (2010). Leadership: What Is it? Sage Publication.

Ogbo, A. I. (2014). The effect of workforce diversity on organizational performance of selected firms in Nigeria. Mediterranean Journal of Social Sciences, 5(10), 231. https://doi.org/10.5901/mjss.2014.v5n10p231

Ohly, S. (2006). Routinization, Work Characteristics and Their Relationships with Creative and Proactive Behaviors. Journal of Organizational Behaviors, 27(3), 257-401. https://doi.org/10.1002/job.376

Opoku, A. (2015). Organizational leadership role in the delivery of sustainable construction projects in the U.K. Built Environment Project and Assets Management, 5(2), 154-169. https://doi.org/10.1108/BEPAM-12-2013-0074

ORDORO BLOG. (2012). Centralized Organization VS Decentralized Organization.

Osgood, C. (2013). Business structures and sustainability: How are they connected? Theguardian.

Pierce, F. (2020). The product life cycle is in decline. Supply Chain.

Popescu, A. M. (2015). Organization's age and organizational citizenship behavior (OCB), performance criteria at SMEs level. Case study - Bucharest - Ilfov development region. Procedia Economics and Finance, 22, 645-654. https://doi.org/10.1016/S2212-5671(15)00278-6

Porter, T. H. (2016). The greening of organizational Culture: Revisited fifteen years later. Emerald Group Publishing Limited. https://doi.org/10.1108/AJB-04-2016-0011

Quain, S. (2019). Basic types of organizational structure: Formal \& informal. Chron.

Reddy, C. (n.d.). Hiring young employees advantages and disadvantages. Wisestep.

Rehman, S. U. (2020). The role of environmental management control system for ecological sustainability and sustainable performance. Management Decision, ahead-of-print. https://doi.org/10.1108/MD-06-2020-0800

Rosengren, W. R. (1968). Organizational age, structure, and orientations towards clients. Social Forces, 47(1), 1-11. https://doi.org/10.2307/2574705

Roth, C. (2009). Who is the older worker? EHSToday Working age population. Data OECD

Sach, J. (2020). Sustainable Development Report 2020. Sustainable Development Report.

Satyendra. (2015). Importance of leadership for Organizational Excellence. ISPATGURU

Saxena, A. (2014). Workforce diversity: A key to improve productivity. Elsevier. https://doi.org/10.1016/S2212-5671(14)00178-6

Saxena, A. (2021). Workforce diversity: A Key to improve productivity. ScienceDirect.

Schaltegger, S. (2016). Business models for sustainability: A co-evolutionary analysis of sustainable entrepreneurship, innovation, and transformation. Organization \& Environment, 29(3), 264-289. https://doi.org/10.1177/1086026616633272

Schreiber, J. B., Nora, A., Stage, F. K., Barlow, E. A., \& King, J. (2006). Reporting structural equation modeling and confirmatory factor analysis results: A review. The Journal of Educational Research. https://doi.org/10.3200/JOER.99.6.323-338

Sengupta, D. (2020). 5 Reasons Why Leadership Is Essential in A Health Work Culture. eLearning Industry.

Shi, L. Y. (2019). The evolution of sustainable development theory: Types, goals, and research prospects. 
Sustainability. https://doi.org/10.3390/su11247158

Soper, D. S. (2015). A-priori Sample Size Calculator for Structural Equation Models. Free statistics calculators.

Source, R. (2018). Management, Social Sustainability, Reputation, and Financial Performance Relationships: An Empirical Examination of U.S. Firms. Organization \& Environment, 32(3), 331-362.

Spiliakos, A. (2018). What does "sustainability" mean in business? Harvard Business School.

Starik, M. (2013). Towards a theory of sustainability management: Uncovering and integrating the nearly obvious. Organization \& Environment, 26(1), 7-30. https://doi.org/10.1177/1086026612474958

Stoughton, A. M. (2012). The driving forces of sustainability. Emerald Group Publishing Limited.

Sullivan, J. (2019). Four basic elements of organizational structure. Chron.

Team, I. E. (2021). Hierarchy Structure: Definition and examples. Indeed Career Guide.

Tellz, D. (2017). Three reasons diversity is important in driving sustainability. Sustainable Brands.

Todorut, A. V. (2012). Sustainable development of organizations through total quality management. Procedia Social and Behavioral Sciences, 62(24), 927-931. https://doi.org/10.1016/j.sbspro.2012.09.157

UKEssays. (2020). Relationship between organizational structure and Culture. UKEssays.

United Nations. (1987). Report of the World Commission on Environment and Development: Our Common Future.

VanAuken, B. (2007). Organization age \& size impact on brand management. The Blake Project.

Vet, J. M. D. (2021). Impact of the COVID-19 pandemic on E.U. industries. European Parliament.

VSOURCE. (2020). The evolution of diversity in the workplace, 2000 to 2020.

Walmsley, T. (2021). The impact of the coronavirus on the economy of the United States. SpringerLink. https://doi.org/10.2139/ssrn.3678835

Ward, S. (2020). What Is Leadership? The small balance business.

Webster, A. L. (2019). Formalization of an organizational structure. Bizfluent.

Westland, J. C. (2010). Lower bounds on sample size in the structural equation. Electronic commerce research and applications.

WGU. (2020). The leadership theories and styles.

Wiernik, B. M. (2016). Age and employee green behaviors: A meta-analysis. Frontiers in Psychology. https://doi.org/10.3389/fpsyg.2016.00194

Wijethilake, C. (2017a). Strategic responses to institutional pressures for sustainability: The role of management control system. Accounting, Auditing \& Accountability Journal, 30(8). https://doi.org/10.1108/AAAJ-07-2015-2144

Wijethilake, C. (2017b). Strategic responses to institutional pressures for sustainability: The role of management control systems. Emerald Publishing Limited. https://doi.org/10.1108/AAAJ-07-2015-2144

Wijethilake, C. (2018). Proactive strategic responses to corporate sustainability pressures: A sustainability control system framework. Advances in Management in Accounting, 30, 129-173. https://doi.org/10.1108/S1474-787120180000030006

Wilson, D. (2018). Understanding the impact of technology on business. Business News / Technology.

Wolf, E. J. (2013). Sample size requirements for structural equation models: an evaluation of power, bias, and solution propriety. Educational and Psychological Measurement, 73(6), 913-934. https://doi.org/10.1177/0013164413495237

Yu, D. K. (2018). The dimensions of organizational character and its impacts on organizational performance in Chinese context. Frontiers in Psychology. https://doi.org/10.3389/fpsyg.2018.01049

Zacher, H. (n.d.). Organizational age cultures: The interplay of chief executive officers age and attitude towards younger and older employees.

Żak, A. (2015). Triple bottom line concept in theory and practice. ResearchGate. https://doi.org/10.15611/pn.2015.387.21

Zimmermann, K. A. (2017). What Is Culture? LIVE SCIENCE. 
Zogjani, J. (2015). The role of leadership in achieving sustainable organizational change and the main approaches of leadership during organizational change. Academic Journal of Interdisciplinary Studies, 4(3), 65. https://doi.org/10.5901/ajis.2015.v4n3p65

\section{Copyrights}

Copyright for this article is retained by the author, with first publication rights granted to the journal.

This is an open-access article distributed under the terms and conditions of the Creative Commons Attribution license (http://creativecommons.org/licenses/by/4.0/). 